\title{
Web Services Selection Based on Mixed Context and Quality of Service Ontology \\ Nabil Keskes (Corresponding author)
}

\author{
University Djillali Liabes of Sidi Bel Abbes, EEDIS Lab, Computer Science Department, Algeria
}

E-mail: kesnab@univ-sba.dz

Ahmed Lehireche

University Djillali Liabes of Sidi Bel Abbes, EEDIS Lab, Computer Science Department, Algeria

E-mail: elhir@univ-sba.dz

Abdellatif Rahmoun

University Djillali Liabes of Sidi Bel Abbes, EEDIS Lab, Computer Science Department, Algeria

E-mail: rahmoun_abd@yahoo.fr

Received: March 29, 2011

Accepted: April 14, 2011

doi:10.5539/cis.v4n3p138

\begin{abstract}
Intensive efforts are made in the Web services selection literature by these days mainly because of the overwhelming interest of the community in the services provided over the Web. In selecting best services, the non functional properties of such services are proven to be more and more important; these describe the Quality of service that is the key factor in the selection process.In this paper, we discuss a Web service selection based on both the context and the QoS ontology. We propose an architecture that makes an automatic selection of best service provider that is based on mixed context and QoS ontology for a given set of parameters of QoS. The key idea is to rely on multi dimensional QoS. Finally, some experiments are run so to demonstrate consistency and effectiveness of the proposed method.
\end{abstract}

Keyword: Web Pragmatic, Selection of Services, Semantic Web Service, Quality of Service, QoS Ontology, Context, Ranking

\section{Introduction}

Recently, the distributed information systems are becoming more and more prominent due to the large impact of the web on the modern society. The evolution of the information technology tools led to the development of new paradigms that describe interactions that exist over IT applications such as Service-Oriented Architecture (SOA). This architecture built using services as software components assuring a particular and accessible functionality through its interface [Michael Mrissa 2005]. However, in the web semantic data and rules are systematically described, after which they can be shared and used by distributed agents. The main components implementing this Web application include techniques such as XML as for adding arbitrary structures to documents; Resource Description Framework (RDF) as to express meaning by simple statements about things having properties with values; and ontology so to formally describe concepts and their relations. A typical ontology is an explicit specification of a conceptualization [Gruber, T 1994]. One of the major functions of the semantic Web is to provide access to web services. These are often described and invoked through central registries. However, for describing, discovering, and composing web services, a semantic approach is proven to be not sufficient. Services cannot be described independently of how they are used, because communities of practice use services in novel unexpected ways. Social mechanisms are therefore needed for evaluating and discovering trustworthy providers and consumers of services, taking into account contexts and interactions in the selection of service applications [Aldo de Moor 2005]. Our goal is to find the best provider of e-service that responds to a request for service. To achieve that, the following steps are required:

- Submit the query with terms and values of quality without and within their context.

- Compare the qualities of provider services with the qualities of request.

- Select the best provider service. 
In the last step, to select the best provider, we first compute the matching degree of published qualities and required qualities for each service without using the context of quality. Second, we make use of the context of quality and compare the two cases [Nabil keskes and al 2010]. For instance, let the web service provider be a service Flight Booking, the providers can be Air France, Airlines Japan and Continental Airlines. Furthermore, there are a set of parameters of QoS to qualify the providers (Reputation, Execution duration, price....). The first service is the French one which deals with the prices in Euro and with a multiplier factor of 1 . The second one is the Japanese service that uses the Yen as currency with multiplier factor of 1000. In the selection process, the prices must be converted in a same currency with a corresponding factor before sending it to the customer. This is to show the importance of context in interpreting the concepts of qualities in selecting processes. Hence, one may ask whether or not the context may influence the selection process? In this paper, we present a service selection based on both the context and the QoS ontology where QoS is multi-dimensional.

The rest of this paper is organized as follows: Section 2 presents web service selection and related works in the current literature, Section 3 presents some concepts on the context, Section 4 presents the proposed approach, Section 5 is devoted to experiments and Section 6 concludes this article.

\section{Related Work}

From a semiotic point of view, there are two ways to deal with Web services: first, an approach based on Web socio semantic [Manuel Zacklad 2005] and the second is an approach based on the pragmatic web [Aldo de Moor and al 2004]. In the first approach, the problem is the engineering of ontology semiotics. They have different criteria for the establishment of agreements defining the construction of ontology from logical approaches, contextual and situational. In the second approach, The Pragmatic Web consists of a set of pragmatic contexts of semantic resources. A pragmatic context consists of a common context and a set of individual contexts. A common context is defined by the common concepts and conceptual definitions of interest to a community, the communicative interactions in which these concepts are defined and used, and a set of common context parameters (relevant properties of concepts, joint goals, communicative situation, and so on). Each community member has also an individual context consisting of individual concepts, definitions of interest and individual context parameters. Meaning plays a central role in connecting the various Webs. Meaning assignment takes place when syntactic resources are semantically enriched such as XML-tags being added to HTML-pages. Meaning alignment is highly concerned with the interoperability across ontologies. Meaning negotiation process should be a consensus seeking process, individual balancing and common requirements. Different individual views on the meaning of common concepts should be allowed, as long as they do not endanger the quality of the communicative interaction. For example, in a business transaction, it is essential that both parties have the same view of crucial parts of the definition of their contract, such as legal obligations. Where and how to store copies of the contract internally does not need to be part of a common meaning, however, we may allow a degree of freedom only if differences in meaning inhibit the accomplishment of common goals. The meaning negotiation will have to proceed until the necessary amount of consensus has been reached.

\subsection{The selection based on the Matchmaking:}

Classification of services deals with ranking. This is accomplished by determining the degree of similarity between the requested services and the provided ones. There exist two approaches in the literature: the description matching of the Description Logic (DL), and the description matching The DARPA agent markup language for services (DAML-S). In the DL approach, matching the specification of Web service uses the description logic, $\mathrm{T}$ is a terminology of e-service $\mathrm{S}$, and a query $\mathrm{Q}$ expressed in a description logic $\mathrm{L}$. We must find a set of e-services E, so that $\mathrm{Q}$ and $\mathrm{E}$ should share as much information as possible. The part of Q not covered by $\mathrm{E}$ must be as small as possible. Additional information provided by $\mathrm{E}$ over $\mathrm{Q}$ must be as small as possible. The semantic difference between $\mathrm{E}$ and $\mathrm{Q}$ must be unique. In some languages like $\mathrm{FL}_{0}$, this is possible, but for much expressive language this difference is rather not unique [Christophe Rey 2002]. In the description Matching DAML-S, two scenarios are used. In the first scenario, a central authority offers a server which provides an interface to the matching algorithm and maintains a semantic database or repository where service providers can register their Web Services. This is similar to the Universal Description Discovery and Integration (UDDI) setup in which the UDDI Business Registry serves as a central database providing Web Service information. In contrast to UDDI, however, with a semantic database or repository service providers do register their services with corresponding DAML-S descriptions (and possibly additional "regular" information which they would provide if registering with the UDDI registry). A client seeking a Web Service connects to the server through some interface and sends its requirements. The server then matches the obtained information against all the available Web Services in its database or repository. When one or more matches are found, the server returns 
the addresses of the appropriate Web Services. In the second scenario, the execution of the matching algorithm takes place locally. This means that the client seeking service is responsible for implementing and maintaining the matching algorithm. The client naturally knows the semantic description of his ideal service, but on the other hand he has to somehow obtain semantic descriptions (i.e. DAML-S documents) of other Web Services in order to match these against his very own requirements. There are basically two possible ways to how the client may get these semantic descriptions: The client manually gets the description, for example from a business partner. The client makes a query to a database or repository which provides semantic information on Web Services. Unlike in scenario 1 , this database does not perform any matching but simply provides semantic descriptions for Web Services. In general, both described ways of obtaining the service descriptions may not be practical. The downfall of the first method is that it requires a certain level of manual interaction. The second method in contrast allows for automatic processing (i.e. querying the database). However, in the worst case, the client has to query the complete database and run the matching algorithm over every single Web Service description to finally find a match. [Michael $\mathrm{C}$ and al 2004]

\subsection{Selection based on Quality of Service ( $Q O S)$}

The classification of services is done by evaluating criteria such as response time, cost, and reputation for delivering such service. Major techniques in the current literature are based on the quality of service. This includes:

$>$ QoScomputing: use of measures, technical standards and numerical calculations to determine the maximum or minimum of an objective function that is used to find the better service [Y.Liu and al 2004] [Padovitz 2005] [Bonatti and al 2005].

$>$ Multi Agent System: the used of the matching algorithm which is based on the concepts of desired quality and provided quality [Maximilien and al 2004 ][ Nabil keskes and al 2010].

$>$ QoS ontology: In this case, ontology is a semantic specification of the quality. In combination with the multi agent system, it provides a common vocabulary for quality and facilitates communication and reasoning among agents specifically brokers agent [Y.Liu and al 2004][ Nabil keskes and al 2010].

\subsection{Selection based on adaptation of context}

Most relevant concepts found in the current literature are summarized as follows:

$>$ [Gandon F and al 2004]:Stress the need to consider knowledge about user preferences and contextual characteristics to seek information. Their approach is based first on a server context that contains information about preferences, and second, the access rights of a user.

$>$ [Behr G and al 2004]: propose a framework that operates on four profiles that describe the characteristics of the content or media (type, format, size, location where the media is stored) of the user (preferences), the device (hardware and software capabilities), network and service (media format supported, network connection, bandwidth, latency and performance.

$>$ [Pashtan and al 2004]: propose to adjust the content delivered by the web service through processing of Extensible Stylesheet Language Transformations (XSLT)

$>$ [Keidl M and al 2004] : proposed an integration of the definition of Simple Object Access Protocol (SOAP) in order to find a web service that is able to meet user needs.

\subsection{Selection based on communities}

$>$ [Hamdi Yahyaoui and al 2008]: In this approach, the authors introduce a reputation-based Web services community architecture and define some of the performance metrics that are needed to assess the reputation of a Web service community as perceived by the users and providers.

$>$ [Marie-Christine Fauve 2008]: This approach proposes a model of communities whose main objective is to allow client applications to select the services which better meet a set of non-functional properties such as quality of service. The model of communities is formalized by a set of abstract data types. Types provide operations which enable service providers to register services to a community and client applications to select services, either at design time or at run time, and those that meet their needs.

\subsection{Selection based on Configurable Web Services}

$>$ [Steffen Lamparter and al 2007]: The selection algorithm ranks the offered services and their configurations according to the requester's preferences and thus facilitates personalized selection strategies. In addition, the approach leverages existing Web standards to provide a maximal degree of interoperability between service 
providers and their customers leading to significant efficiency gains. The approach is implemented prototypically and the performance is evaluated by means of a simulation.

\subsection{Selection based on trust}

[E. Michael Maxim lien and al 2004]: Service selection should be determined based on user preferences and business policies, and consider the trustworthiness of service instances. This approach is based on an architecture and programming model in which agents represent applications and services.

$>$ [Stefania Galizia and al 2007]: In this approach, the authors propose a methodology for addressing trust in Semantic Web Services (SWS)-based applications. The aim is to enhance the capability-driven selection provided by current SWS frameworks with the introduction of trust-based selection criteria. They present ontology - Web Services Trust Ontology (WSTO) - which models the context of a trust-based interaction and enables the participants to describe semantically their trust requirements and warrantees.

\section{QoS Ontology and Context}

The QoS ontology is used to give meaning to the terms of quality. There are three types of QoS Ontology. The first one is QoS upper ontology: this captures the concepts of the highest generic quality and defines the basic concepts that are related to quality. The second one is QoS middle ontology which introduces aspects of quality discovered in distributed systems. Finally, the lower QoS ontology: this contains the qualities of the domain.

In our work, we always associate context to quality. Moreover, this condition justifies the adoption of a definition of context, namely:"the context of data includes all internal or external elements which is relative to the data that is necessary to the correct interpretation of the data". We distinguish three approaches for modelling of context: The first consists to store the context using a set of couples (attribute, value). The Context Toolkit proposed by [Dey A. K and al 2001] uses this approach. The second approach presents the context using RDF. This approach presents an extension of the Composite Capability/Preference Profiles (CC / PP) W3C profile [J. Indulska and al 2003] proposed by Held [Held. A 2002]. The third approach uses the ontology for modelling the context. The most elaborate model is Context Ontology Language (CoOL) [Paolo Pasinelli 2003]. This represents the context similar to a set of entities having some aspects that describe their features. Table 1 presents a global view of these 3 approaches with their strength and weaknesses. In this paper, and for sake of simplicity, we choose the first approach mainly because of the diversity of the contexts in a multi dimensional QoS. Furthermore, we may say that a formal and practical model of the context is not available. In the applications sensitive to the context, big efforts are provided to define how to capture the context to the system. Unfortunately, there is no precise answer of how to combine the QoS with the context. This is where this paper is supposed to give contribution.

\section{The proposed solution}

In Web services applications, ontology is used to represent the semantics of data and forms a consensus on a common vocabulary. Our work is based on the use of context to facilitate the process of selection between services. We propose an architecture which uses different qualities of services, and gives the appropriate interpretation for these qualities in their respective context. To do this, we first introduce some relevant related basic concepts.

\subsection{Similarity measures: Measure based on the interpretation of concepts}

In [D'amatoc, fanizzi 2006] the authors proposed a similarity measure of the concepts described in logic, and defined as follows:

$$
s(C, D)=\frac{|C \cap D|^{I}}{|C|^{I}+|D|^{I}-|C \cap D|^{I}} \times \max \left(\frac{|C \cap D|^{I}}{|C|^{I}}, \frac{|C \cap D|^{I}}{|D|^{I}}\right)
$$

Where $(.)^{I}$ is a function of interpretation and $|$.$| is the cardinal of a set. This measure is relevant because it$ verifies the semantic properties such as the similarity between two equivalent concepts $(C \equiv D)$ is equal to 1 .

\subsection{The proposed architecture}

Figure 1 shows the proposed architecture. It consists of a set of agents: Matchmaker Agents, Mediator Agent, and a Rankmaker Agent. The process of selection is described as follows:

1- Matchmaker Agent consults the required qualities and the published qualities,

2- Matchmaker Agent uses QoS ontology to match the required qualities and the published qualities,

3- This Agent sends the result by a message to the mediator agent, 
4- Mediator Agent receives the message that contains the result and stores it in a Database. This agent connects with Database by using the driver jdbc: odbc.

5- Rankmaker Agent consults this Database and measures the ranking by using Algorithm [Xia Wang and al $2006]$ in two stages with and without context.

6- Finally, RankMaker sends the results to the consumer.

The primary task of this architecture is ranking through using the proposed algorithm in [Xia Wang and al 2006] in two stages without using context and with context. This is resumed as below:

\section{The first step: performing without using context}

We assume that $Q_{R}=\left\{r_{1}, r_{2}, \ldots \ldots \ldots r_{k}\right\}$ expresses the profile of a user's quality requirements, which includes $k$ quality metrics. Similarly, the quality profile of $m$ candidate services in set $S$ is denoted as

$Q_{S}=\left\{Q_{A 1}, Q_{A 2}, \ldots \ldots.\right\} \quad$ where $Q_{A i}=\left\{q_{i 1}, q_{i 2}, \ldots \ldots . q_{i j}\right\} i, j \in N$.

Therefore, the matrix of QoS for service matchmaking $\quad M_{Q}=\left\{Q_{R}, Q_{A 1}, \ldots \ldots . Q_{A m}\right\}$ with the quality requirements $Q_{R}$ in the first row, and the quality information of candidates services in the other rows. For uniformity, matrix $M_{Q}$ has to be normalized [Xia Wang and al 2006], i.e., the elements of the matrix are real numbers in the range $[0,1]$. The result matrix is $M_{Q}$. Finally, we compute the evaluation result for each quality metrics by summing the values of each rows. These abstract values are taken as a relative evaluation of each service's QoS.

$$
\mathrm{M}_{\mathrm{Q}^{\prime \prime}}=\mathrm{M}_{\mathrm{Q}^{\prime}} \times \mathrm{W}=\sum_{\mathrm{I}=1}^{\mathrm{M}}\left(\mathrm{q}_{\mathrm{ij}} \times \mathrm{w}_{\mathrm{j}}\right)
$$

where $W=\left\{w_{1}, w_{2}, \ldots \ldots \ldots \ldots, w_{n}\right\}$, and $\mathrm{w}$ represents the weighted value for each quality metrics.

\section{The second step: performing with context}

We use the semantic distance (equation 1) because this distance may introduce the required interpretation in this method. The following example illustrate this step: the data in table 2 are presented with three quality criteria, Price, Compensation Rate, and Reputation. Their corresponding value types are euro, percent, and rank value in the range $[0,5]$. We assume a request of a service customer and other four services for testing.

We assume that there are three cases of context:

- The Context of Quality Price for customer (table 3) [Michael Mrissa 2005]

- The Context of Quality Price for services (table 4)

- We assume that the context of ComRat is empty in our case study.

- The context of reputation in table5: [Yao Wang and al 2007] trust and reputation both depend on some context. For instance, Mike trusts John as his doctor, but he does not trust John as a mechanics to fix his car. So in the context of seeing a doctor, John is trustworthy, but in the context of fixing a car, John is untrustworthy.

The result of normalisation [Xia Wang and al 2006 ] without using context of the first service for the quality price is:

$$
\mathrm{dm}=1-(25-25) /(55-25)=1
$$

The interpretation of the concept price in its context is:

Customer:

Context ( currency="euro", TAXincluded="true", taxRat="19, 6\%", Countryname="France")

First Service:

Context ( currency="euro", TAXincluded="false", taxRat=17\%, Countryname="France")

The interpretation of required quality in first context is: $\quad C_{1}{ }^{\mathrm{I}}=$ \{“euro"," true","19, 6","France")

The interpretation of published quality in second context is:

$\mathrm{C}_{2}{ }^{\mathrm{I}} \quad$ = ‘"euro"," false","17","France")

$\mathrm{C}_{1}{ }^{\mathrm{I}} \cap \mathrm{C}_{2}{ }^{\mathrm{I}}=\{$ "euro", "France" $\}$, cardinality $\left(\mathrm{C}_{1}{ }^{\mathrm{I}}\right)=4, \quad$ cardinality $\left(\mathrm{C}_{2}{ }^{\mathrm{I}}\right)=4$, and

Cardinality $\left(\mathrm{C}_{1}^{\mathrm{I}} \cap \mathrm{C}_{2}^{\mathrm{I}}\right)=2$

We apply equation (1)

$\mathrm{s}\left(\mathrm{C}_{1}, \mathrm{C}_{2}\right)=2 /(4+4-2) * \max (1 / 2,1 / 2)=1 / 3 * 1 / 2=1 / 6=0.17$ 
The degree of match with context is:

Average $=(\mathrm{dm}+\mathrm{s}(\mathrm{c} 1, \mathrm{c} 2)) / 2=(1+0.17) / 2=0.585$.

in this case, the context presents additional information, therefore we compute the degree of matching without QoS ontology, then we take the average match degree that specifies the relation existing between the context and the quality of service.

\section{Experimental results}

In our experiment, data are provided from [Y.Liu and al 2004] and [Xia Wang and al 2006], the authors implement hypothetical phone service (UPS). Four phone services, in table 6 test data are presented with seven qualities:

The result of the normalization for these four services (ABC, BTT, A1, A2) is:

$$
Q^{\prime}=\left\{\begin{array}{ccccccl}
1 & 1 & 0.870 & 0.500 & 0.571 & 0.621 & 0 \\
0.500 & 1 & 1 & 1 & 0 & 1 & 0.250 \\
0.900 & 1 & 0.522 & 0 & 1 & 0 & 0.500 \\
0 & 1 & 0 & 0.667 & 0.429 & 0.188 & 1
\end{array}\right\}
$$

Assuming that $W=\{4,0,0,2,1,1,2\}$, therefore, from (2) the quality evaluation is computed as follows:

$$
Q^{\prime \prime}=\sum_{i=1}^{m}\left(q_{i j} \times w_{i}\right)=\{6.196,5.500,5.600,3.951\}
$$

First, we observe that the result of selection with seven qualities is the same as with five qualities. The qualities with null weighted values can be ignored. This is expressed by the following equations:

If $\mathrm{l}=\operatorname{card}(\mathrm{wk}=0)$ with $(\mathrm{k}, \mathrm{l})<=m \Rightarrow \sum_{i=1}^{m}\left(\mathrm{q}^{\prime} \mathrm{ij} \times \mathrm{wi}\right)=\sum_{i=1}^{m-l}\left(\mathrm{q}^{\prime} \mathrm{ij} \times \mathrm{wi}\right)$

$\sum_{i=1}^{m}\left(\mathrm{q}^{\prime} \mathrm{ij} \times \mathrm{wi}\right)=\sum_{i=1}^{m-l}\left(\mathrm{q}^{\prime} \mathrm{ij} \times \mathrm{wi}\right)+\sum_{i=(m-l)+1}^{m}\left(\mathrm{q}^{\prime} \mathrm{ij} \times \mathrm{wi}\right)$

The problem comes to prove that:

If $\mathrm{L}=\operatorname{card}(\mathrm{wk}=0)$ with $(\mathrm{k}, \mathrm{l})<=m \quad \Rightarrow \sum_{i=(m-l)+1}^{m}\left(\mathrm{q}^{\prime} \mathrm{ij} \times\right.$ wi $)=0$

$\sum_{i=(m-l)+1}^{m}\left(\mathrm{q}^{\prime} \mathrm{ij} \times \mathrm{wi}\right)=0 \quad \Rightarrow \quad \sum_{i=1}^{l}\left(\mathrm{q}^{\prime} \mathrm{ij} \times \mathrm{wi}\right)=0$

Since $\mathrm{L}=$ card $(\mathrm{wk}=0)$, then:

$\forall i \in\{1, \ldots, L\}, \mathrm{Wi}=0 \Rightarrow \mathrm{q}^{\prime} \mathrm{ijwi}=0 \Rightarrow \sum_{i=1}^{l} \mathrm{ijwi}=0 \quad$. This is what was needed to prove

From this proof, we observe that one can use only five qualities, whereas, in table 7 we may make use of experiment data with five qualities.

Second, we also observed that we may be able to reduce the number of qualities up to three, especially for the qualities having high weighted values $(4,2,2)$. Using the same example with three qualities CompRat, PenRat, Repu that are uniformly distributed (using for example the 'runif' function in R language.

Normalization and the QoS of table 7 is as illustrated in the table8. In table 9 we can find the results of ranking procedure with 5 qualities, and in table 10 we can find The results of normalization and QoS with three qualities (price, ComRat, Reput),and table11 shows results of ranking procedure with three qualities. Through this example, we observe that for these four services, the result with three qualities is the same as with five. To check this hypothesis, we apply the Kolmogorov-Smirnov test, and in table 12 we repeated this experiment five times with random values generated by function "runif" of language $\mathrm{R}$ as mentioned before. For entries $\mathrm{n}=4$ and $\alpha=0.05$, the value of doorstep according the statistics table Kolmogorov-Smirnov is 0.6239 . In our experiment $\mathrm{D}=\max \left|F_{n}(x)-F(x)\right|=999999874$; that is higher than 0.6239. This shows that the result for five qualities is the same as for with three qualities. We repeated this experiment for 5, 6, 7, 8 and 10 services. The table 13 resumes the results. Through those experiments, it is shown that when the number of services is higher than six, the value of $\mathrm{D}$ is smaller than 0.6239 , therefore we may say that the hypothesis is accepted up to six services, that is; the selection of web services using three qualities (price, ComRat, Repu) is well adapted up to six services.

Finally, to illustrate this approach, we propose a purchasing scenario so to demonstrate consistency and effectiveness of the proposed method. In table 14, there are six providers $S_{1}$ to $S_{6}$, all of them providing the same services. The evaluation of quality of services is made by multi-dimensional QoS. The second, third, and fourth columns represent respectively price, Compensation Rate, and Reputation. The fifth, sixth, and seventh columns represent the normalization of quality; the eighth column is the current values of each QoS. 
Following the proposed method in section 4.2, we first start with identifying the effect of the context on the selection of services based on QoS. In the first time, the context is not used; the results obtained after calculating QoS are illustrated in the figure2 Following this step, we rely on the context to select the best service for a particular request. The results obtained are illustrated in the figure3.

In Figure 2, the best service is $S_{3}$ and in Figure 3 it is $S_{2}$. Through this example, we notice that the context affects the process of selection. Furthermore, we repeat this experiment thirty one times. We try to check the dependencies existing between the two major variables: QoS modality with context and QoS modality without context. In all those experiments, we observed that the ranking procedure without context is different that with context. We make use of the $\chi^{2}$ test. In this experiment, the observed frequency is 31 , the theoretical frequency is $1-\frac{31}{(720)^{31}}$ and $\chi^{2} \cong 0$; this means that we can accept the hypothesis of dependencies. We may assert that the QoS depends on the context. Future work will emphasize on extending the proposed method by increasing the number of services in the selection process. We implemented computer simulation of several scenarios using jade [http://jade.tilab.com] for implementing agents and Jena [http://jena.sourceforge.net] for interaction with ontology, and finally $\mathrm{R}$ language for generating random values.

\section{Conclusion}

This paper proposed a new scheme of selection of web services based on both context and the QoS ontology. This is done by proposing an architecture that makes an automatic selection of best service provider that is based on mixed context and QoS ontology for a given set of parameters of QoS. We first showed that the performance of selecting web services using three quality services is similar to the one using up to seven quality services. Moreover, other experiments demonstrate that the QoS is strongly dependent of the context. Furthermore, future work may emphasize on the effect of increasing the number of qualities (higher than three), and the effect of increasing the number of services (higher than six) on the process of selection of web services based on both context and the QoS ontology.

\section{References}

Aldo de Moor. (2005). Patterns for the Pragmatic Web, in Proceeding of the 13th International Conference on Conceptual Structures (ICCS2005), Kassel, Germany, pp.1-18, 2005.

Aldo de Moor, van den Heuvel. (2004). Web service selection in virtual communities, System Sciences Proceedings of the 37th Annual International Conference, Hawaii, on Volume, Issue Page(s): 10, [Online] Available: http://doi.ieeecomputersociety.org/10.1109/HICSS.2004.1265468.

Behr G, Brunei L., Pierson J.M. (2004). Modeling Service-Based Multimedia Contents Adaptation in Pervasive Computing, Actes de la 1ere Conference Computing Frontiers, Ischia, Italie, ACM Press, pp 60-90, ISBN: 1-58113-741-9 doi $>10.1145 / 977091.977102$.

Bonatti, P. Festa. (2005). On Optimal Service Selection, Proceedings of the 14th international conference on World Wide Web, Chiba, Japan, pp.530 - 538, ISBN:1-59593-046-9 doi>10.1145/1060745.1060823

Christophe Rey. (2002). Dynamic discovery of e-services: a Description Logics based approach. Symposium on the Effectiveness of Logic in Computer Sciences (ELICS02) in Honour of Moshe Vardi Poster Presentation. March 4 - 6, Saarbruecken. Germany, ISBN:1-59593-046-9 doi>10.1145/1060745.1060823.

D'amatoc, fanizzi. (2006). A dissimilarity measure for ALC concept descriptions, SAC'06: Proceedings of the 2006 ACM symposium on Applied computing, New York, USA, ACM Press, pp 1695-1699, ISBN:1-59593-108-2 doi>10.1145/1141277.1141677.

Dey A. K., Salber D. and Abowd G. D. (2001). A Conceptual Framework and a Toolkit for Supporting the Rapid Prototyping of Context-Aware Applications. Human-Computer Interaction Journal 16(2-4), pp. 97-166, doi $>10.1207 /$ S15327051HCI16234_02.

E. Michael Maxim lien, Munindar P. Singh. (2004). Toward Autonomic Web Services Trust and Selection ICSOC'04, November 15-19, pp212-221 ,2004, New YorkUSA. ACM 2004 1-58113-871-7/04/0011, [Online] Available: http://citeseerx.ist.psu.edu/viewdoc/summary?doi=10.1.1.69.5157.

Gandon F. Sadeh N. (2004). Semantic Web Technologies to Reconcile Privacy and Context A wareness. Journal of Web Semantic, vol .1, n3,pp.241-260, doi:10.1016/j.websem.2003.07.008 Key: citeulike:1019436.

Gruber, T. (1994). Towards Principles for the Design of Ontology Used for Knowledge Sharing. IEEE Transactions on Software Engineering, 16 (11): pp 1282-1292, [Online] Available: http://citeseerx.ist.psu.edu/viewdoc/summary?doi=10.1.1.89.5775. 
Hamdi Yahyaoui and al. (2008). On the Reputation of Communities of Web Services, NOTERE 2008 June 23-27, 2008, Lyon, France, ACM pp. 9-16, ISBN: 978-1-59593-937-1 doi>10.1145/1416729.1416735.

Held. A. (2002). Modeling of Context Information for Pervasive Computing Applications. Proc. 6th World Multiconference on Systemics, Cybernetics and Informatics (SCI2002), Orlando, FL, pp. 167-180 July. [Online] Available: http://citeseer.ist.psu.edu/viewdoc/summary?doi=10.1.1.20.3976.

J. Indulska, Robinson R., Rakotonirainy A., and Henricksen K. (2003). Experiences in Using CC/PP in Context-Aware Systems .Proc. 4th Intl. Conf. on Mobile Data Management, Melbourne, Australia, pp. 247-261.

January.

[Online]

Available:

http://citeseer.ist.psu.edu/viewdoc/summary;jsessionid=6498FB22CF76D94F40A96ED3DCE6F202?doi=10.1.1. 12.4426 .

Keidl M., Kemper A. (2004). Toward Context-Aware Adaptable Web Services, Actes de 13eme conference WWW, New York, ,USA, pp. 55-65, ISBN:1-58113-912-8 doi>10.1145/1013367.1013378.

Manuel Zacklad. (2005). Introduction aux ontologies sémiotiques dans le Web Socio Sémantique In: JAULENT,M,-C, 16emes journées francophones d'ingenerie des connaissances,30-03 avril 2005,NICE.Grenoble : PUG, 2005,p12.

Marie-Christine Fauvet. (2008). Sélection dynamique de services Web - une approche à base de communautés; projet Web Intelligence - Cluster ISLE - Région Rhône-Alpes; France; pp. 505-520.

Maximilien and P. Singh. (2004). Multi agent System for Dynamic Web Services Selection, IEEE Internet Computing, _Volume 8, Issue 5, pp84- 93, [Online] Available: http://citeseerx.ist.psu.edu/viewdoc/summary?doi=10.1.1.67.2076.

Michael C. Jaeger, Stefan Tang. (2004). Ranked Matching for Service Descriptions using DAML-S, .pp 217-228, Workshops: Riga, Latvia - Vol. 3, [Online] Available: http://citeseerx.ist.psu.edu/viewdoc/summary?doi=10.1.1.88.3787.

Michael Mrissa. (2005). Médiation Sémantique Orientée Contexte pour la Composition de Services Web, International Journal of Web and Grid Services 1(3/4):pp268-286, Inderscience, 2005.

Nabil keskes, Ahmed Lehireche, and Abdellatif Rahmoun. (2010). Web Services Selection Based on Context Ontology and Quality of Services, International Arab Journal of e-Technology, Vol. 1, No. 3, January 2010.

Padovitz, S. Krishnaswamy, S. Wai Loke. (2005). Towards Efficient Selection of Web services, 17th IEEE International Conference on Volume, Issue, 16-16 Nov, Page(s):5 pp. - 376, [Online] Available: http://doi.ieeecomputersociety.org/10.1109/ICTAI.2005.122.

Paolo Pasinelli. (2003). Service Interoperabil-ity on Context Level in Ubiquitous Computing Environments.seminaries, [Online] Available: http://diuf.unifr.ch/pai/education/2002_2003/seminar/summer/report/Pasinelli201103.pdf,pp1-6,

Pashtan A. Heusser A, Sheuermann P. (2004). Personal Service Areas For Mobile Web Applications. IEEE Internet Computing, vol .8, n 6, pp 34-39, doi:10.1109.

Stefania Galizia, Alessio Gugliotta and John Domingue. (2007). A Trust Based Methodology for Web Service Selection, ICSC '07 Proceedings of the International Conference on Semantic Computing IEEE Computer Society Washington, DC, USA, ISBN:0-7695-2997-6 , pp.193-200 ， ISBN:0-7695-2997-6 doi>10.1109/ICSC.2007.8.

Steffen Lamparter, Anupriya Ankolekar. (2007). Automated Selection of Configurable Web Services Proceedings of the 16th international conference on World Wide Web, ACM New York, NY, USA, ISBN: 978-1-59593-654-7, pp.441-458, [Online] Available: http://citeseerx.ist.psu.edu/viewdoc/summary?doi=10.1.1.73.6109.

Xia Wang and al. (2006). A QoS-aware Selection Model for Semantic Web Services, ICSOC 2006 ,Volume 4294, pp 390-401, Spring-Vertag Berlin Heideberg, [Online] Available: http://citeseerx.ist.psu.edu/viewdoc/summary?doi=10.1.1.93.4360.

Yao Wang, Julita Vassileva. (2007). Toward Trust and Reputation Based Web Service Selection: A Survey, Proc International Transactions on Systems Science and Applications ITSSA Journal Volume: 3, Issue: 2, [Online] Available: http://citeseerx.ist.psu.edu/viewdoc/summary?doi=10.1.1.89.6365. 
Y.Liu, A. H.H. Ngu. (2004). QoS Computation and Policing in Dynamic Web Service Selection,_Proceedings of the 13th international World Wide Web conference on Alternate track papers \& posters. New York, NY, USA, pp 66 - 73, [Online] Available: http://citeseerx.ist.psu.edu/viewdoc/summary?doi=10.1.1.2.1739.

Table 1. Different schemes of modelling the context: strengths and weaknesses

\begin{tabular}{|c|c|c|c|}
\hline $\begin{array}{c}\text { Feature of the } \\
\text { model }\end{array}$ & $\begin{array}{c}\text { Expressivity of } \\
\text { semantics }\end{array}$ & $\begin{array}{c}\text { Ease of } \\
\text { implementation }\end{array}$ & $\begin{array}{c}\text { Resistance to } \\
\text { the conflicts }\end{array}$ \\
\hline $\begin{array}{c}\text { Couple } \\
\text { (attribute, value) }\end{array}$ & - & + & - \\
\hline RDF & + & + & - \\
\hline Ontology & + & - & + \\
\hline
\end{tabular}

Table 2. Example of test data

\begin{tabular}{|c|c|c|c|}
\hline & Price & ComRat & Repu \\
\hline R & 30 & 0,4 & 4 \\
\hline ABC & 25 & 0,5 & 2 \\
\hline BTT & 40 & 0,8 & 2,5 \\
\hline A1 & 28 & 0,2 & 3 \\
\hline A2 & 55 & 0,6 & 4 \\
\hline
\end{tabular}

Table 3. Context of Quality Price (Customer)

\begin{tabular}{|c|c|c|c|c|}
\hline Pri & Currency & Tax-included & Tax Rate & CountryName \\
\hline $\mathrm{R}$ & euro & true & $19,6 \%$ & France \\
\hline
\end{tabular}

Table 4. Context of Quality Price(Providers)

\begin{tabular}{|c|c|c|c|c|}
\hline pri & Currency & Tax-included & TaxRate & CountryName \\
\hline ABC & euro & false & $17 \%$ & France \\
\hline BTT & euro & true & $17 \%$ & France \\
\hline A1 & euro & false & 19,6 & France \\
\hline A2 & euro & true & 19,6 & France \\
\hline
\end{tabular}

Table 5. Context of Quality Reputation

\begin{tabular}{|c|c|}
\hline reputation & Context \\
\hline $\mathrm{ABC}$ & false \\
\hline $\mathrm{BTT}$ & true \\
\hline $\mathrm{A} 1$ & false \\
\hline $\mathrm{A} 2$ & true \\
\hline
\end{tabular}


Table 6. Experimental data

\begin{tabular}{|l|c|c|c|c|c|c|c|}
\hline data & pri & tran & Time out & ComRat & PenRat & Execu & Reput \\
\hline R & 30 & 1 & 80 & 0.4 & 0.8 & 120 & 4.0 \\
\hline ABC & 25 & 1 & 60 & 0.5 & 0.5 & 100 & 2.0 \\
\hline BTT & 40 & 1 & 200 & 0.8 & 0.1 & 40 & 2.5 \\
\hline A1 & 28 & 1 & 140 & 0.2 & 0.8 & 200 & 3.0 \\
\hline A2 & 55 & 1 & 180 & 0.6 & 0.4 & 170 & 4.0 \\
\hline
\end{tabular}

Table 7. experiment data with five qualities

\begin{tabular}{|c|c|c|c|c|c|}
\cline { 2 - 6 } \multicolumn{1}{c|}{} & Pri & CompRat & PenRat & Execu & Repu \\
\hline $\mathrm{S}_{1}$ & 25 & 0,6 & 0,6 & 95 & 2,0 \\
\hline $\mathrm{S}_{2}$ & 34 & 0,8 & 0,1 & 40 & 3,0 \\
\hline $\mathrm{S}_{3}$ & 40 & 0,2 & 0,8 & 200 & 2,1 \\
\hline $\mathrm{S}_{4}$ & 55 & 0,7 & 0,7 & 64 & 4,0 \\
\hline
\end{tabular}

Table 8. Normalization(With five qualities)

\begin{tabular}{|c|c|c|c|c|c|c|}
\hline & Pri & CompRat & PenRat & Execu & Repu & QoS \\
\hline $\mathrm{S}_{1}$ & 1,000 & 0,623 & 0,658 & 0,658 & 0,000 & 6,561 \\
\hline $\mathrm{S}_{2}$ & 0,698 & 1,000 & 0,000 & 1,000 & 0,485 & 6,764 \\
\hline $\mathrm{S}_{3}$ & 0,500 & 0,000 & 1,000 & 0,000 & 0,060 & 3,119 \\
\hline $\mathrm{S}_{4}$ & 0,000 & 0,854 & 0,866 & 0,849 & 1,000 & 5,424 \\
\hline
\end{tabular}

Table 9. result of ranking with 5 qualities

\begin{tabular}{|l|l|}
\hline Service & QoS \\
\hline $\mathrm{S}_{2}$ & 6.764 \\
\hline $\mathrm{S}_{1}$ & 6.561 \\
\hline $\mathrm{S}_{4}$ & 5.424 \\
\hline $\mathrm{S}_{3}$ & 3.119 \\
\hline
\end{tabular}

Table 10. normalization(with three qualities)

\begin{tabular}{|c|c|c|c|}
\hline Pri & CompRat & Repu & QoS \\
\hline 1,000 & 0,623 & 0,000 & 5,245 \\
\hline 0,698 & 1,000 & 0,485 & 5,764 \\
\hline 0,500 & 0,000 & 0,060 & 2,119 \\
\hline 0,000 & 0,854 & 1,000 & 3,709 \\
\hline
\end{tabular}


Table 11. result of ranking with three qualities

\begin{tabular}{|l|l|}
\hline Service & QoS \\
\hline $\mathrm{S}_{2}$ & 5.764 \\
\hline $\mathrm{S}_{1}$ & 5.245 \\
\hline $\mathrm{S}_{4}$ & 3.709 \\
\hline $\mathrm{S}_{3}$ & 2.119 \\
\hline
\end{tabular}

Table 12. Kolmogorov-Smirnov test for four services

\begin{tabular}{|c|c|c|c|c|c|}
\hline $\begin{array}{c}\text { Observed Distribution } \\
(\mathrm{F}(\mathrm{x}))\end{array}$ & 1,00 & 1,00 & 1,00 & 1,00 & 1,00 \\
\hline $\begin{array}{c}\text { Theoretical Distribution } \\
\left(F_{n}(x)\right)\end{array}$ & 0,0417 & 0,001736 & $7,2 \mathrm{E}-05$ & $3,01 \mathrm{E}-06$ & $1,25587 \mathrm{E}-07$ \\
\hline$D$ & 0,9583 & 0,998264 & 0,99993 & 0,999997 & 0,999999874 \\
\hline
\end{tabular}

Table 13. Kolmogorov-Smirnov test for 5,6,7,8 services

\begin{tabular}{|c|c|}
\hline $\mathrm{N}=$ number of services & $\mathrm{D}$ \\
\hline 5 & 0,99999999 \\
\hline 6 & 0,998611111 \\
\hline 7 & 0,000198413 \\
\hline 8 & $2,48016 \mathrm{E}-05$ \\
\hline 10 & 0.5000000 \\
\hline
\end{tabular}

Table 14. Experimental Data

\begin{tabular}{|c|c|c|c|c|c|c|c|}
\hline & pri & ComRat & Repu & \multicolumn{3}{|c|}{ Normalization } & QoS \\
\hline $\mathrm{S}_{1}$ & 25 & 0,3 & 2,0 & 1,000 & 0,205 & 0,000 & 4,410 \\
\hline $\mathrm{S}_{2}$ & 33 & 0,6 & 4,0 & 0,731 & 0,648 & 0,976 & 6,173 \\
\hline $\mathrm{S}_{3}$ & 27 & 0,8 & 2,7 & 0,936 & 1,000 & 0,332 & 6,407 \\
\hline $\mathrm{S}_{4}$ & 31 & 0,2 & 2,7 & 0,806 & 0,000 & 0,341 & 3,905 \\
\hline $\mathrm{S}_{5}$ & 54 & 0,6 & 3,7 & 0,024 & 0,743 & 0,847 & 3,278 \\
\hline $\mathrm{S}_{6}$ & 55 & 0,6 & 4,0 & 0,000 & 0,649 & 1,000 & 3,298 \\
\hline
\end{tabular}




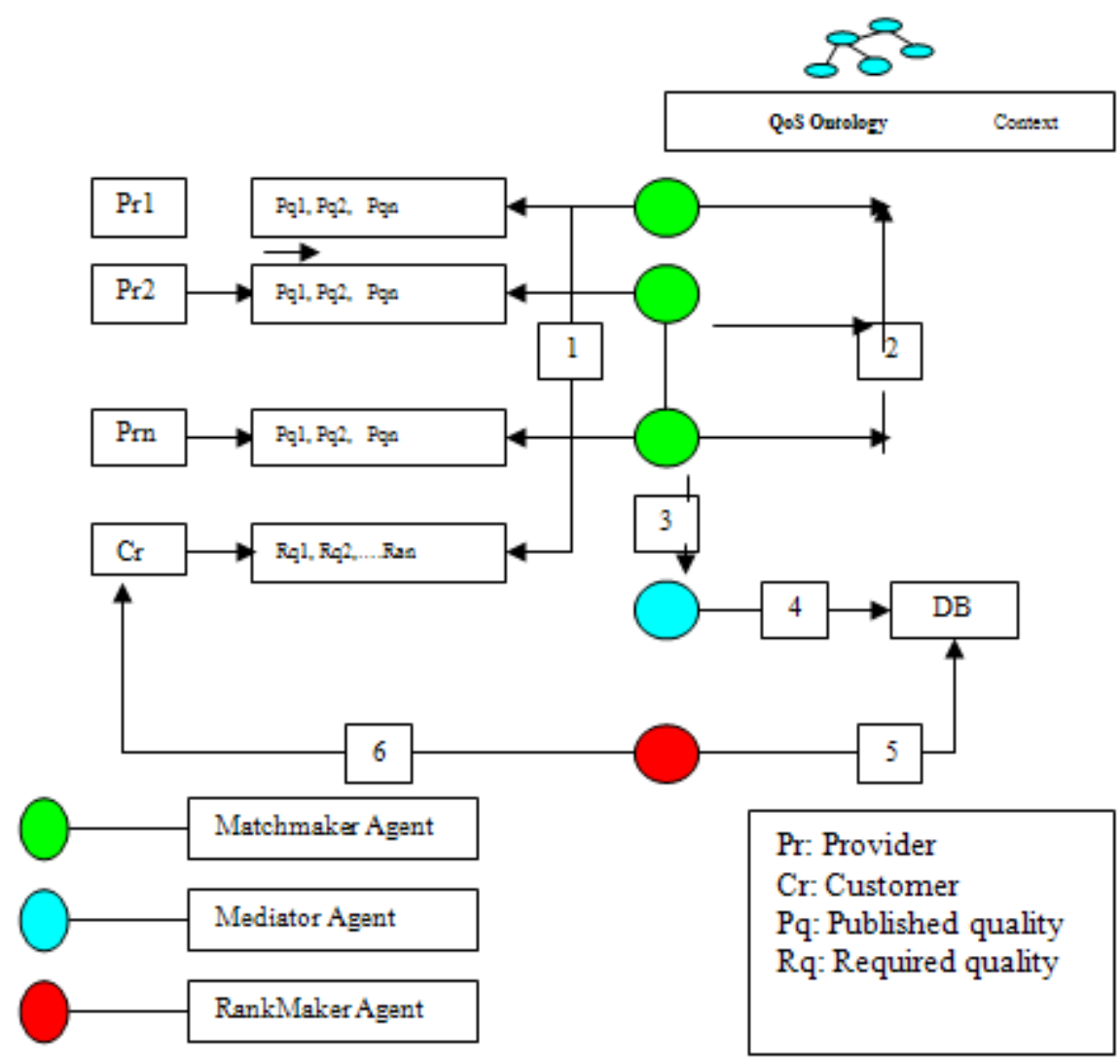

Figure 1. The proposed architecture

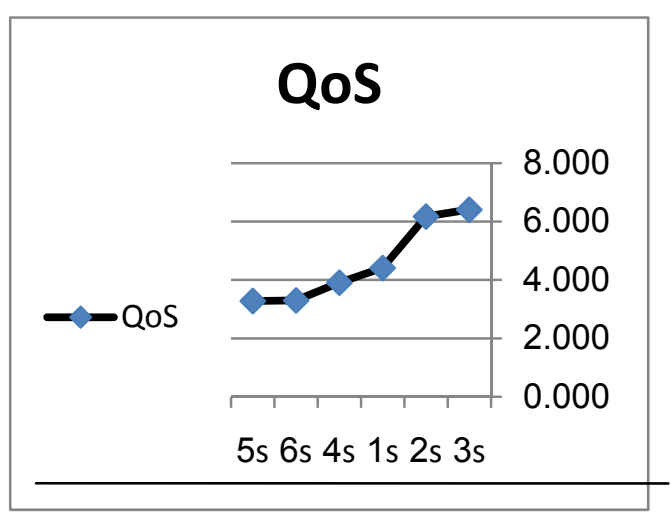

Figure 2. evaluation of qualities of 6 services without using context 


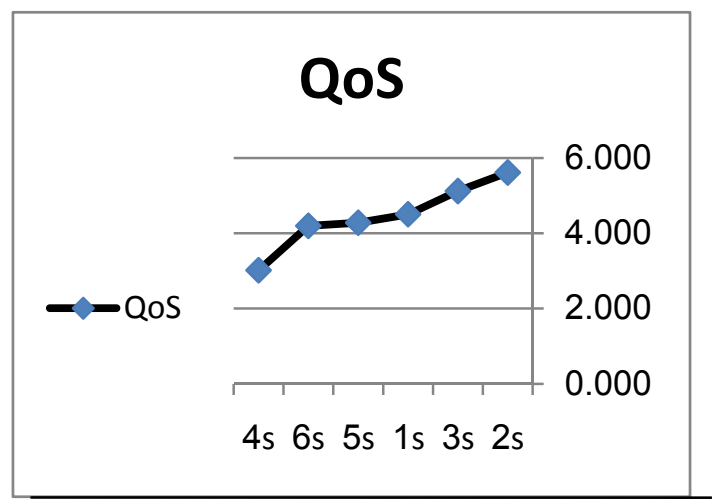

Figure 3. evaluation of qualities of 6 services with use context 